\title{
Quantification of Survey Expectations by means of Symbolic Regression via Genetic Programming to Estimate Economic Growth in Central and Eastern European Economies
}

\author{
Oscar Claveria ${ }^{1}$, Enric Monte ${ }^{2}$, Salvador Torra ${ }^{3}$ \\ ${ }^{1}$ AQR-IREA, University of Barcelona (UB) \\ ${ }^{2}$ Department of Signal Theory and Communications, Polytechnic University of Catalunya (UPC) \\ ${ }^{3}$ Riskcenter-IREA, Department of Econometrics and Statistics, University of Barcelona (UB)
}

\section{Oscar Claveria}

AQR-IREA (Institute of Applied Economics Research)

University of Barcelona

Diagonal, 690

08034 Barcelona

Spain

Tel.: +34-934021825

oclaveria@ub.edu

\section{Enric Monte}

Department of Signal Theory and Communications

Polytechnic University of Catalunya

Jordi Girona, 1-3

08034 Barcelona

Spain

Tel.: +34-934016435

enric.monte@upc.edu

Salvador Torra

Riskcenter-IREA

University of Barcelona

Diagonal, 690

08034 Barcelona

Spain

Tel.: +34-934024318

storra@ub.edu

\footnotetext{
* Corresponding Author:

Oscar Claveria, University of Barcelona, 08034 Barcelona, Spain. Email: oclaveria@ub.edu
} 


\title{
Quantification of Survey Expectations by means of Symbolic Regression via Genetic Programming to Estimate Economic Growth in Central and Eastern European Economies
}

\begin{abstract}
Tendency surveys are the main source of agents' expectations. The main aim of this study is twofold. First, we propose a new method to quantify survey-based expectations by means of symbolic regression (SR) via genetic programming. Second, we combine the main SR-generated indicators to estimate the evolution of GDP, obtaining the best results in the Czech Republic and Hungary. Finally, we assess the impact of the 2008 financial crisis, finding an improvement in the capacity of agents' expectations in most Central and Eastern European economies to anticipate economic growth after the crisis.
\end{abstract}

Keywords: Symbolic regression; Evolutionary algorithms; Genetic programming; Tendency surveys; Survey-based expectations; Economic Climate Indicators; Forecasting

Jel classification: C51; C53; C55; C63; C83; C93; E27 


\section{Introduction}

Agents' expectations about the state of the economy play a major role in economic time series modelling. Business and consumer surveys provide detailed information about agents' expectations. Survey-based expectations present several advantages over experimental expectations. First, they are based on the knowledge of the respondents operating in the market. Second, they are available ahead of the publication of quantitative official data. Third, they provide detailed information about a wide range of variables. Tendency surveys ask respondents whether they expect a certain variable to increase, to remain constant or to decrease. Survey results are published as aggregated data. The individual replies can be aggregated as percentages of the respondents in each category, or re-scaled by means of a grading procedure. In both cases, the qualitative nature of survey results has led to quantify agents' responses making use of survey indicators.

The most commonly used indicator to present survey results is the balance statistic. By assuming that the expected percentage change in a variable remains constant over time for all agents, Anderson (1951) defined the balance statistic as the subtraction between the percentage of agents reporting an increase and the percentage of those reporting a decrease. As the balance statistic does not take into account the percentage of respondents expecting a variable to remain constant, Claveria (2010) proposed a variation of the balance statistic that accounts for this percentage of respondents by weighting it by the proportion of respondents expecting a variable to rise or fall. The weighted balance allows discriminating between two equal values of the balance statistic depending on the percentage of respondents expecting a variable to remain constant. By matching individual responses with firm-by-firm outcomes, Müller (2010) finds evidence that the median of the "no change" category is equal to zero. Visco (1984) and Papadia (1983) calculate balances for surveys with more than three answering categories.

The balance statistic has been widely used in applied economics, both as the regressors in quantitative forecasts models (Guizzardi and Stacchini, 2015; Martinsen et al., 2014; Ghonghadze and Lux, 2012; Robinzonov, 2012; Lui et al., 2011a,b; Schmeling and Schrimpf, 2011; Franses et al., 2011; Klein and Özmucur, 2010; Graff, 2010; Claveria and Datzira, 2010; Claveria et al., 2007; Abberger, 2007; Mitchell et al., 2005a; Hansson et al., 2005; Mittnik and Zadrozny, 2005; Batchelor and Dua, 1998; Kauppi et al., 1996; Parigi and Schlitzer, 1995; Bergström, 1995; Rahiala and Teräsvirta, 1993; Biart and 
Praet, 1987), and also to test economic hypothesis (Girardi, 2014; Jean-Baptiste, 2012, Zárate et al., 2012; Schmeling and Schrimpf, 2011; Jonsson and Österholm, 2011, 2012; Paloviita, 2006; Pesaran and Weale, 2006; Lemmens et al., 2005, 2008; Pehkonen, 1992; Ivaldi, 1992; Batchelor and Dua, 1992; Ilmakunnas, 1989; Pesaran, 1987, 1985, 1984).

The balance statistic can be regarded as a qualitative measure of the average changes expected in the variable. As a result, numerous methods to transform balances into a quantitative measure of agents' expectations have been proposed in the literature. The output of these quantification procedures is a proxy of unobservable expectations, and therefore they inevitably entail a measurement error (Lee, 1994).

The first approach for quantifying survey expectations proposed by Theil (1952) is based on the assumption that respondents report a variable to go up or down if the mean of their subjective probability distribution lies above or below a threshold level or indifference interval. This method is known as the probability approach. Carlson and Parkin (1975) suggested using a normal distribution together with symmetric and constant threshold parameters, both across respondents and over time. The proposed extensions of the Carlson-Parkin framework are mainly focused on relaxing some of its assumptions. See Lahiri and Zhao (2015), Vermeulen (2014), Pesaran and Weale (2006), Driver and Urga (2004), and Nardo (2003) for an appraisal of the different quantification methods.

This study presents a novel method to quantify survey data on expectations based on evolutionary computation and symbolic regression (SR). A SR-based approach allows to identify non-linear dependencies between expectations about different economic variables in large datasets. We estimate the SR model by means of genetic programming (GP), which through Darwinian competition selects the fittest models of interaction between agents' expectations. The main objective of this research is to propose a method to empirically model agents' expectations so as to generate predictions of the evolution of the economy. With this aim, we make use of survey data from the World Economic Survey (WES) carried out by the CESIfo Institute for Economic Research in co-operation with the International Chamber of Commerce.

The relationship between changes in expectations and economic growth has been widely investigated (Mokinski et al., 2015; Dees at al., 2013; Leduc and Sill, 2013; Lui, Mitchell and Weale, 2011a,b; Zanin, 2010; Claveria et al., 2007; Abberger, 2007; Nolte and Pohlmeier, 2007; Mitchell et al., 2005a,b), but never before by means of SR. By combining a SR approach with GP, we are able to identify the optimal combinations of a wide range of survey variables that best fits the actual evolution of the gross domestic 
product (GDP) in a set of countries of the Organisation for Economic Co-operation and Development (OECD).

SR is an empirical modelling approach especially suitable when the model structure is unknown or changes over time. While conventional regression analysis is based on a certain model specification that optimizes the coefficients in the model, SR does not rely on a specific a priori determined model structure. SR can optimize the model structure and the coefficients simultaneously. SR finds an appropriate model from a space of all possible expressions defined by a set of given operations and functions. The only assumption made in SR is that the response surface can be described by an algebraic expression. The application of GP (Koza, 1992) in SR has allowed to apply empirical modelling in a wide range of applications.

GP can be considered as an extension of genetic algorithms (GAs) based on variablelength trees instead of fixed-sized individuals. GP belongs to the class of evolutionary algorithms (EAs), which were introduced by Holland (1975) and fostered by evolutionary programming (Fogel et al., 1966). Zelinka (2015) provides an overview of EAs. See Fogel (2006) and Goldberg (1989) for applications and a comprehensive overview.

Empirical modelling via SR with GP is increasingly attracting interest from different areas due to its wide applicability (Cai et al., 2006; Yao and Lin, 2009, Vladislavleva et al., 2010; Can and Heavey, 2011; Barmpalexis et al., 2011; Ceperic et al., 2014; Sarradj and Geyer, 2014). Nevertheless, the applications in economics are still few. Kotanchek et al. (2010) identify models between large public datasets and GDP per capita. Kronberger et al. (2011) use SR to identify variable interactions in a large dataset of economic indicators to estimate US inflation. Kl'účik (2012) uses GP in the estimation of total exports and imports to Slovakia via SR. Wei (2013) proposes a hybrid model to forecast the stock index in Taiwan. Yang et al. (2015) propose a data-driven approach that uses SR to forecast oil production.

We aim to break new ground by implementing SR via GP in modelling agents' expectations. This approach allows us to quantify survey expectations and generate estimates of GDP growth.

The structure of the paper is as follows. Section 2 reviews the literature on the quantification of survey expectations. Section 3 presents our methodological approach. In Section 4 an overview of the experiment is given. Section 5 describes the data. In Section 6 we present the empirical results. Finally, a brief summary together with the conclusions are given in Section 7. 


\section{Literature review on the quantification of survey-based expectations}

Business and consumer surveys, also known as tendency surveys, are characterized by asking agents about whether they expect a variable to rise, to fall, or to remain unchanged. The qualitative nature of agents' responses has led to quantify survey indicators. Anderson (1952) was the first to formalise the relationship between actual changes in a variable and respondents' expectations by regressing the actual average percentage change of an aggregate variable $Y_{t}$, on the percentage of respondents expecting a variable to rise and fall, denoted by $R_{t}$ and $F_{t}$ respectively. This regression approach was latter extended by Pesaran (1984) by allowing the model for an asymmetrical relationship between the actual average percentage change of an aggregate variable $y_{t}$ and the change for agent $i\left(y_{i t}\right)$ in periods of growth.

The most common approach for quantifying survey expectations is assuming that respondents report a variable to go up or down if the mean of their subjective probability distribution lies above or below a threshold level (indifference interval). This theoretical framework was proposed by Theil (1952), and denoted as the probability approach. Carlson and Parkin (1975) developed the method by using a normal distribution. Several authors have used alternative distributions (Batchelor, 1982; Visco, 1984; Foster and Gregory, 1987). Mitchell (2002), Berk (1999), Balcombe (1996) and Fishe and Lahiri (1981) have found evidence that normal distributions provide as accurate expectations as other stable distributions. The Carlson-Parkin method assumed a constant and symmetric indifference interval across respondents and over time.

Pesaran (1987), Bennett (1984), Batchelor (1981, 1982), and Defris and Williams (1979) noted some of the restrictions of the Carlson-Parkin framework. Abberger (2007) uses probit analysis to estimate a quantitative threshold for employment expectations that allows to differentiate between a decrease and an increase in actual employment. Several refinements of the probabilistic approach have been proposed in order to reduce the measurement error introduced by restrictive assumptions (Lahiri and Zhao, 2015; Breitung and Schmeling, 2013; Łyziak, 2013; Müller, 2010; Mitchell, Mouraditis and Weale, 2007; Claveria et al., 2003, 2006; Mitchell, Smith and Weale, 2002, 2005; Löffler, 1999; Berk, 1999; Smith and McAleer, 1995; Dasgupta and Lahiri, 1992; Kariya, 1990; Batchelor and Orr, 1988; Seitz, 1988; Batchelor, 1986; Toyoda, 1979). 
By making the threshold dependent on time-varying quantitative variables, Batchelor (1986), and Berk (1999) developed a variant of the Carlson-Parkin procedure. Seitz (1988) used Cooley and Prescott's (1976) time-varying parameter (TVP) model, in which the parameter vector was subject to permanent and temporary shocks. Claveria et al (2006) presented a more general model based on a state-space representation that allows for asymmetric and dynamic response thresholds generated by a first-order Markov process.

A certain amount of literature has focused on individual expectations. Mitchell, Smith and Weale (2002) developed an indicator based on firm-level responses. By comparing the individual responses with firm-by-firm realisations, Müller (2010) develops a variant of the Carlson-Parkin method with asymmetric and time invariant thresholds. The author introduces the "conditional absolute null" property, which is based on the empirical finding that the median of realized quantitative values corresponding to the "no change" category is zero. The main advantage of this new procedure is that it solves the zero response problem and that provides variance estimates closer to the sample variances. As opposed to the results obtained by Lui et al. (2011a), Müller (2009) finds that business expectations provide useful information. For an an appraisal of individual firm data on expectations see Zimmermann (1997).

Recent studies for Central and Eastern countries are those of Sorić, Škrabić, and Čižmešija (2013) who assess the predictive properties of the composite indicators of the business and consumer surveys of the European Commission for the EU. The authors compare the forecasting performance of old EU members states vs. the new members states by means of panel vector autoregressive models, finding no significant differences in both groups. These results somehow contrast to those obtained by Łyziak and Mackiewicz-Łyziak (2014) who in a using a panel data analysis find that the weight of future inflation in the formation of expectations in transition economies was smaller, which could in part be attributed to the higher volatility inflation rates in those countries.

In a recent study, Lahiri and Zhao (2015) propose a generalization of the CarlsonParkin method that allows time-varying and heterogeneous thresholds. The authors examine the quality of quantified expectations by comparing them to quantitative realizations at the firm-level, finding that allowing for cross-sectional heterogeneity and asymmetric and time-varying thresholds significant improvements are obtained, particularly during periods of uncertainty, with high levels of disagreement between respondents. 
As stated by Lee (1994), the differences between the actual values of a variable and quantified expectations may arise from three different sources: measurement or conversion error due to the use of quantification methods, expectational error due to the agents' limited ability to predict the movements of the actual variable, and sampling errors. Since survey-based expectations are approximations of unobservable expectations, they inevitably entail a measurement error.

Monte Carlo simulations allow to distinguish between these three sources of error. Nevertheless, there have been few attempts in the literature to compare quantification methods in a simulation context. Common (1985) and Nardo and Cabeza-Gutés (1999) analyse different quantification methods focusing on rational expectation testing rather than on their forecasting ability. Nardo (2003) and Claveria et al. (2006) assess the forecasting performance of different quantification methods in simulation experiments. By means of simulation-based expectations, Terai (2009) and Löffler (1999) estimate the measurement error introduced by the probabilistic method.

\section{Methodology - Symbolic regression via evolutionary computation}

\subsection{Symbolic Regression}

SR attempts to find relationships biding together variables of a given dataset. It is a regression method where no model is assumed beforehand. The solution is based on discrete optimization, searching for the most fitting algebraic expression to the data (in the space of all possible expressions). Koza (1992) proposed the application of GP to implement SR. There are different strategies for solving a SR. GP is the most common approach due to its versatility. SR is particularly indicated when there is little information available about the process under consideration.

The wide applicability of this approach is attracting researchers from different areas (Sarradj and Geyer, 2014; Ceperic, Bako and Baric, 2014; Barmpalexis et al., 2011; Wu, Chou and Su, 2008; Cai et al., 2006;). SR plays an increasingly important role in many engineering applications, such as signal processing (Yao and Lin, 2009), industrial data analysis (Vladislavleva et al., 2010), and experimental design of manufacturing systems (Can and Heavey, 2011).

The first application of SR via GP in economics is that of Koza (1992), who uses hierarchical genetic algorithms to analyse the non-linear "exchange equation" relating the 
price level, gross national product, money supply, and velocity of money. The author finds the relationship between quarterly values of the price level in the US (from 1959 to 1988) and the three other elements of the equation. Since then, there have been only a few applications to economics. Álvarez-Díaz and Álvarez (2005) make use of GP to generate predictions of exchange rates of the yen and the pound to the US dollar.

Kotanchek et al. (2010) detect outliers and identify models in large public datasets. The authors use SR via Pareto GP to identify records which are systematically under-or over-predicted by diverse ensembles of (thousands of) global non-linear symbolic regression models. Both approaches applied to the CountryData produce insights into outlier vs. prototypes division among world countries and about driving economic properties predicting gross domestic product (GDP) per capita.

Kronberger et al. (2011) use SR to identify variable interactions in a large dataset of economic indicators to estimate US CPI inflation. Kl'účik (2012) uses GP in the estimation of foreign trade (total exports and imports to Slovakia) via SR. AcostaGonzález et al. (2012) apply GP to select the best econometric model for explaining the severity of the 2008 crisis.

More recently, Wei (2013) proposes a hybrid model that uses an adaptive expectation GA to optimize an adaptive network-based fuzzy inference system (ANFIS) to forecast stock price trends (the stock index in Taiwan). Yang et al. (2015) propose a data-driven approach that uses SR to forecast oil production. Hao et al. (2015) develop a GA-based learning approach to analyse survey data related to customer satisfaction with online travel agencies websites. Chen et al. (2015) also use an adaptive GA (AGA) to hybridize a SVR model. The authors find that the proposed AGA seasonal SVR outperforms AGASVR and BPNN models to forecast holiday daily tourist flows to a site in China (Mountain Huangshan).

\subsection{Genetic Programming}

GP belongs to the broader class of evolutionary algorithms (EAs). EAs can be classified in genetic algorithms (GAs) (Holland, 1975) and GP (Cramer, 1985). While basic GAs use the fixed length binary string representation to code potential solutions of a problem, not allowing the model structure to vary during the evolution, GP uses a more general representation scheme, using tree-structured, variable length representations suitable to nonlinear modelling. A recent economic application of GAs 
is that of Acosta-González and Fernández (2014), who use a GA to forecast the financial failure of firms.

GP can be considered as an extension of GAs. GP was introduced by Cramer (1985). The works of Koza $(1992,1995)$ enabled to apply them to other areas such as $\mathrm{AI}$ and machine learning. Koza (1992) first proposed the use of GP to find a regression tree defining analytical functions that best fit the data. The author suggest that finding the functional form of the models that best fits observed empirical data (instead of selecting the model a priori as in conventional modelling) can be regarded as searching for the computer program which produces the desired output for given inputs (that best fits the observed data). The author proposes finding the best single computer program (the solution to the problem) by applying a Darwinian competition based on the principle of survival and reproduction of the fittest.

GP is an evolutionary method that imitates aspects of biological evolution to find a computer program that solves a given problem through gradual evolutionary changes (Koza, 1992). In GP, populations of computer programs are bred using Darwinian competition and genetic operations. The competition is based on the principle of survival and reproduction of the fittest. By means of genetic operators (crossover and mutation) the structure is evolved and optimized for making it more appropriate for model approximation. Computer programs are mated so as to create potentially more fit new offspring programs. The best single individual program produced by this process after many generations may be a satisfactory solution to the problem. Dabhi and Chaudhary (2015) and O’Neil et al. (2010) review the main issues related to GP.

New improved versions of GP have been proposed in the literature. Ferreria (2001) introduced gene expression programming (GEP). Peng et al. (2014) propose an improved gene expression programming (GEP) algorithm especially suitable for dealing with SR problems. GEP is developed by Ferreira (2001). Zelinka (2005) introduces analytical programming, and shows its ability to synthesize suitable solutions (programs) in SR. Gandomi and Roke (2015) compare the forecasting performance of ANN models to that of GEP techniques. Poli et al. (2010) review the state of the art in GP.

This approach is particularly indicated to find patterns in large data sets, where little or no information is known about the system. GP is capable to evolve the structure of the models in combination with the parameters of the model. In our case, the use of GP is justified by the fact that if there is an arbitrary functional relationship between a large 
data set of variables, which are ordinal variables from surveys, and a macroeconomic objective measure, which is the GDP. This way, we are able to find the "fittest" combinations of surveys variables that are more adequate to track the evolution of the economy.

\section{Experimental setup}

In this study we present a new quantification procedure of economic expectations in the form of survey indicators, such as the balance or the CESIfo indicators. This new method is based on SR via GP. This flexible approach finds optimal combinations of responses or survey variables that describe a quantitative variable used as a yardstick, in our case the year-on-year growth of the GDP. In the present study we use agent's expectations from the CESIfo WES and GDP data retrieved from the OECD web (https://data.oecd.org/gdp/quarterly-gdp.htm\#indicator-chart).

The main objective of the experiment is twofold. On the one hand, we aim to quantify agents' expectations expressed in the form of survey indicators by means of SR approach. Given the functional expression, we obtain building blocks, which can be regarded as parts of the formula, and that are defined as simple combinations of input variables by means of basic functions. We have extracted building blocks for the top 20 functions returned by the GP algorithm for 28 countries of the OECD, focusing the analysis on ten Central and Eastern European economies, for which we combine the most fitted empirical models to generate forecasts of economic growth.

The application of GP requires is based on the following steps:

1. The selection of the independent variables. In our case the 12 variables of the WES presented on Table 1.

2. The set of functions to be used. We have restricted the experiment to the mean, the maximum, the minimum, the ratio, and the logarithm.

3. The definition of a fitness measure that reflects to what extent the individual function reproduces the data used for the regression. As an error metric we have applied the root mean squared error (RMSE).

4. The setting of the parameters that control the run, and deciding what termination criterion to be used. We have chosen a population of 1000, and have limited the maximum number of generations to 150 . 
As a result, the best individual functions from all generations are selected. In this study we have implemented a fully configurable simple EA set up using the open source Distributed Evolutionary Algorithms Package (DEAP) framework implemented in Python.

\section{Data}

The WES is carried out quarterly by the CESIfo Institute for Economic Research. The survey questionnaire focuses on qualitative information. Respondents are asked to assess their country's general situation and expectations regarding important economic indicators (overall economy, foreign trade, inflation, interest rates, share prices, etc.). The individual replies are combined for each country without weighting. The grading procedure consists in giving a grade of 9 to positive replies, a grade of 5 to indifferent replies, and a grade of 1 to negative replies. The survey results are published as aggregated data. The aggregation procedure is based on country classifications. Within each country group or region, the country results are weighted according to the share of the specific country's exports and imports in total world trade (CESifo World Economic Survey, 2011). For a detailed analysis of WES data see Henzel and Wollmershäuser (2005), Stang1 (2007, 2008) and Hutson et al. (2014). Table 1 shows all the variables used in this study. We conduct the experiment from the second quarter of 2000 to the first quarter of 2014.

Table 1. World Economic Survey - Expectations

\begin{tabular}{ll}
\hline Variable & Expectation \\
\hline GSON & Present economic situation - overall economy \\
GSCN & Present economic situation - capital expenditures \\
GSPN & Present economic situation - private consumption \\
GSOP & Economic situation last year - overall economy \\
GSCP & Economic situation last year - capital expenditures \\
GSPP & Economic situation last year - private consumption \\
GSOF & Economic situation next 6 months - overall economy \\
GSCF & Economic situation next 6 months - capital expenditures \\
GSPF & Economic situation next 6 months - private consumption \\
TVEX & Foreign trade volume next 6 months - exports \\
TVIM & Foreign trade volume next 6 months - imports \\
TBAL & Trade balance next 6 months \\
\hline
\end{tabular}


The Economic Climate Index (ECI) is an aggregate indicator obtained as the arithmetic mean of assessments of the general economic situation and the expectations for the economic situation in the next six months. As a rule, the trend in the Ifo ECI correlates closely with the actual business-cycle trend measured in annual growth rates of real GDP. Franses et al. (2011) compare experts forecasts with pure model forecasts. Robinzonov et al. (2012) use the Ifo Business Climate and other aggregate indicators from surveys as exogenous variable for industrial production forecasting. In Table 2 we present a descriptive analysis of the ECI for the ten Central and Eastern European economies evaluated in this study: Bulgaria, Croatia, Czech Republic, Estonia, Hungary, Latvia, Lithuania, Poland, Romania, Slovak Republic.

Table 2. Descriptive statistics ECI (2000:Q2- 2014:Q1)

\begin{tabular}{lccccc}
\hline & mean & $\begin{array}{c}\text { standard } \\
\text { deviation }\end{array}$ & $\begin{array}{c}\text { variation } \\
\text { coefficient (\%) }\end{array}$ & minimum & maximum \\
\hline Bulgaria & 5.45 & 1.09 & 19.9 & 2.60 & 7.70 \\
Croatia & 4.41 & 1.11 & 25.1 & 2.00 & 6.50 \\
Czech Republic & 5.75 & 1.11 & 19.3 & 3.40 & 7.60 \\
Estonia & 6.05 & 1.33 & 21.9 & 2.10 & 8.50 \\
Hungary & 4.83 & 1.11 & 23.0 & 2.80 & 7.80 \\
Latvia & 5.48 & 1.33 & 24.3 & 2.30 & 7.80 \\
Lithuania & 6.15 & 1.40 & 22.7 & 1.50 & 8.00 \\
Poland & 5.67 & 1.23 & 21.6 & 3.50 & 7.70 \\
Romania & 4.85 & 1.38 & 28.4 & 2.00 & 7.40 \\
Slovak Republic & 5.76 & 1.14 & 19.9 & 2.90 & 7.90 \\
\hline
\end{tabular}

\section{Results}

In this section we present the results of how all these survey variables interact to approximate the evolution of the GDP in ten Central and Eastern European countries. First, we visually compare the evolution of the proposed SR-generated indicator to that of the ECI (Fig. 1) and the GDP (Fig. 2). Second, we analyse the forecasting performance of the quantified expectations in ten Central and Eastern European countries by comparing them to a naïve model used as a benchmark to compute the mean absolute scaled error (MASE). Results of this comparison are presented in Table 3. 
Fig. 1. Evolution of Ifo Economic Climate indicator vs. proposed survey-based economic indicator

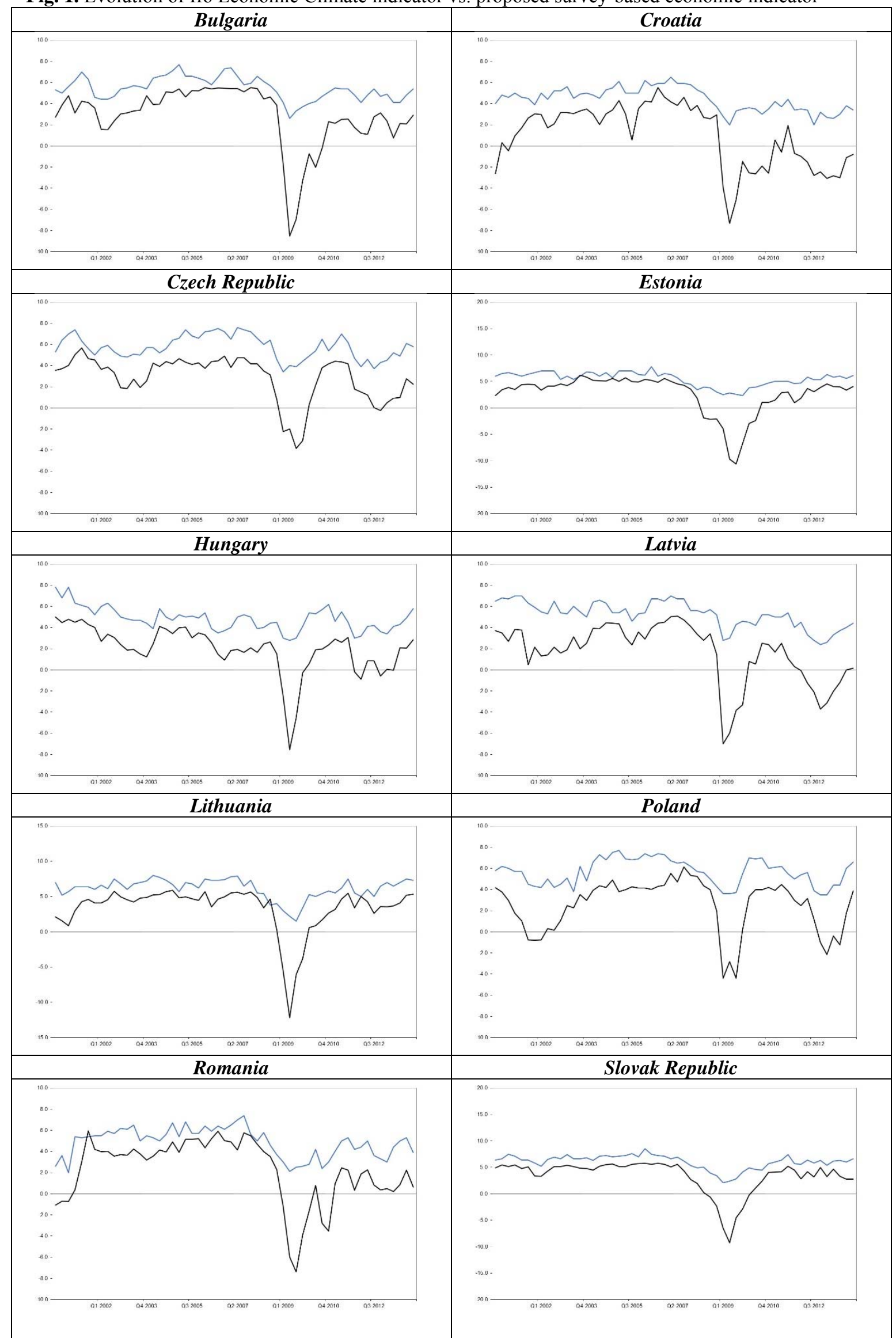

1. Note: Compiled by the author. The grey line represents the evolution of the Ifo Economic Climate indicator in each country. The black line represents the evolution of the proposed SR-based economic indicator via SR. 
Fig. 2. Evolution of year-on-year GDP growth rates vs. proposed survey-based economic indicator

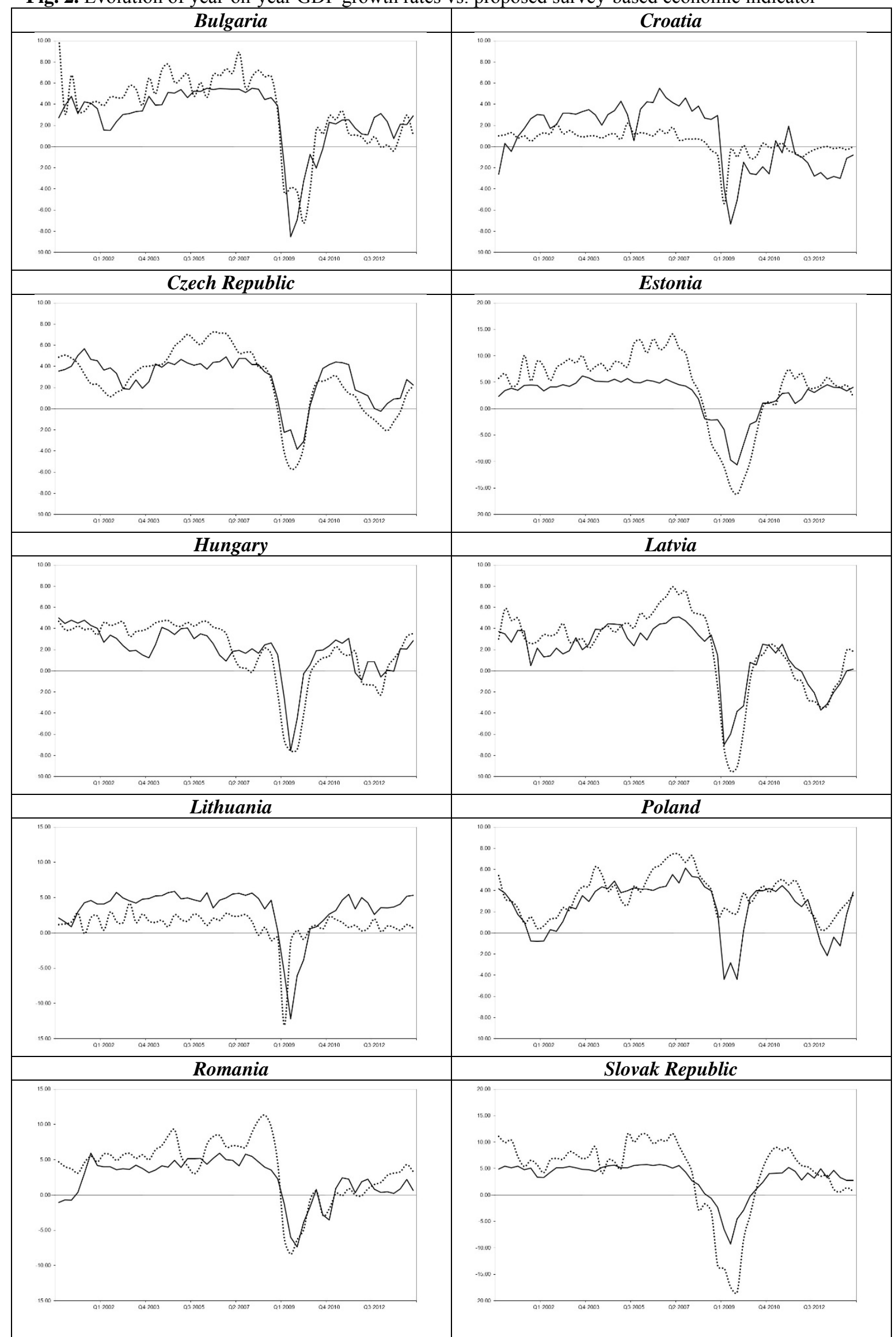

2. Note: Compiled by the author. The dotted line represents the year-on-year growth rate of GDP in each country. The black line represents the evolution of the proposed survey-based economic indicator via SR. 
On Fig. 1 we can see that the proposed SR-generated indicator and the CESIfo ECI both show a similar pattern of evolution. The main difference resides in the scale. This is especially evident during the 2008 financial crisis, when the quantified expectations' downward reaction is of greater magnitude. With the aim of assessing the ability of the proposed proxy of agents' expectations to approximate GDP growth, in Fig. 2 we compare the evolution of the quantified expectations via SR to the evolution of the yearon-year growth rates of GDP in the ten Central and Eastern European economies analysed.

Regarding the differences across the analysed economies, while in most countries agents' expectations seem to advance turning points, especially regarding the 2008 financial crisis, in Bulgaria, Hungary, Latvia and the Slovak Republic the opposite holds. As a rule, SR-quantified expectations seem to correlate closely with the actual oscillations of GDP. These results are in line with those of Lahiri and Zhao (2015), who note the potential gains in forecast accuracy of quantified expectations under more relaxed assumptions.

In Table 3 we compare the forecast accuracy of the quantified expectations used as a proxy for GDP growth between the different economies using the naïve method as a benchmark. In order to do so we use the Mean Absolute Scaled Error (MASE) proposed by Hyndman and Koehler (2006). This measure of forecast accuracy scales the errors by the in-sample MAE obtained with a random walk. As official data are published with a delay of more than a quarter with respect to survey data, we use two-step ahead naïve forecasts as a benchmark. This measure is independent of the scale of the data, and it does not suffer from some of the problems presented by other relative measures of forecast accuracy such as the relative MAE (Hyndman and Koehler, 2006).

Additionally, this statistic is easy to interpret: values larger than one are indicative that the quantified agents' expectations are worse than the average forecast computed insample with the benchmark model. SR-quantified expectations show the best forecasting performance in the Czech Republic and Hungary, where SR-based estimates outperform the naïve model used as a benchmark.

Given that the 2008 financial crisis influenced the forecasting accuracy of surveybased measures of economic expectations (Łyziak and Mackiewicz-Łyziak, 2014), we recompute the MASE differentiating between the pre-crisis sub-period (2000-2007), the crisis (2007-2010), and the post-crisis sub-period (Table 4). 
Table 3. Forecast accuracy by country - 10 Eastern European countries

\begin{tabular}{llll}
\hline & MASE & & MASE \\
\hline Bulgaria & 1.060 & Latvia & 1.230 \\
Croatia & 3.590 & Lithuania & 2.221 \\
Czech Republic & $\mathbf{0 . 9 9 1}$ & Poland & 1.130 \\
Estonia & 1.068 & Romania & 1.065 \\
Hungary & $\mathbf{0 . 9 1 3}$ & Slovak Republic & 1.019
\end{tabular}

Notes: * MASE stands for the Mean Absolute Scaled Error. Below one values (in bold) indicate better predictions than the average two-step forecast computed in-sample with the Naïve method.

Table 4. Forecast accuracy by country - 10 Eastern European countries

\begin{tabular}{llll}
\hline MASE & Pre-crisis & Crisis & Post-crisis \\
\hline Bulgaria & 1.032 & 1.354 & $\mathbf{0 . 7 5 7}$ \\
Croatia & 3.273 & 4.931 & 2.596 \\
Czech Republic & 1.124 & $\mathbf{0 . 7 3 6}$ & 1.029 \\
Estonia & $\mathbf{0 . 9 3 3}$ & 1.550 & $\mathbf{0 . 7 5 8}$ \\
Hungary & $\mathbf{0 . 8 6 9}$ & 1.092 & $\mathbf{0 . 7 8 2}$ \\
Latvia & 1.338 & 1.548 & $\mathbf{0 . 6 1 7}$ \\
Lithuania & 1.885 & 2.668 & 2.371 \\
Poland & $\mathbf{0 . 8 8 5}$ & 1.604 & 1.056 \\
Romania & 1.093 & 1.231 & $\mathbf{0 . 8 0 2}$ \\
Slovak Republic & $\mathbf{0 . 8 1 5}$ & 1.773 & $\mathbf{0 . 5 1 3}$ \\
\hline
\end{tabular}

Notes: * See Notes of Table 3.

The results in Table 4 show that forecast accuracy of survey-based expectations significantly worsened during the crisis in all countries except the Czech Republic. Agents' expectations were more accurate in the post-crisis years than in the pre-crisis years in all countries except in Lithuania and Poland. These results are in line with those of Łyziak and Mackiewicz-Łyziak (2014), who also found that the 2008 financial crisis period has led to a decrease in expectational errors in transition economies. In the last sub-period, SR-quantified expectations outperform the naïve model in six out of the ten countries. At the opposite end, in Croatia and Lithuania, agents' expectations quantified by means of SR via GP are less able to anticipate the year-on-year growth rates of GDP. This result could be explained in part by the high dispersion observed in the ECI (Lithuania presents the highest rang, and Croatia the second highest variation coefficient). Additionally, in the case of Lithuania, mean square errors values were very high, indicating that forecast errors are highly concentrated in a few periods. 


\section{Summary and conclusions}

Economic expectations have become essential to assess the current state of the economy. Survey expectations are a primary source of agents' economic expectations. However, qualitative expectations are usually quantified in order to forecast macroeconomic aggregates or to test economic hypothesis. In this study we propose an empirical approach to the quantification of qualitative survey responses. This data-driven method of modelling survey-based agents' expectations avoids making assumptions about the subjective probability distribution of respondents.

With this aim, we use symbolic regression via genetic programming to derive a set of mathematical functional forms that link survey expectations of the World Economic Survey and economic growth. By linearly combining these expressions, we generate estimates of GP growth in ten Central and Eastern European economies. Finally, we analyse the impact of the 2008 financial crisis on agents' expectations, by assessing the capacity of survey-based expectations to anticipate future economic growth, finding that the crisis period has led to an improvement in the forecasting performance of agents' expectations in Central and Eastern European economies.

We find that the SR-quantified expectations correlate closely with the actual oscillations of the economic activity and with the CESIfo Economic Climate Index. This result shows that this assumption-free approach to quantify survey expectations on the direction of change may provide gains in forecast accuracy. Since empirical modelling with symbolic regression via genetic programming allows selecting the fittest models of interaction between agents' expectations and the official quantitative series they refer to, this approach may prove very useful both for researchers and practitioners.

Despite the usefulness of the proposed framework for forecasting and for quantifying survey-based expectations, this study is not without limitations. One aspect that has not been addressed is the use of this approach to search for the optimal proxy indicator of the quantitative variable used as a yardstick. Another issue left for future research is the use of this new set of quantified expectations to test economic hypothesis, which would provide new insight into the formation of expectations or the behaviour of the Phillips curve. 
Extending the analysis to the rest of the countries of the World Economic Survey would allow to analyse differences across countries worldwide. It would also be of interest to replicate the experiment using micro data. A comparison with other questionnaires would allow to analyse whether the obtained functional forms are extensive to different survey data. Another question to be considered in further research is whether the implementation of alternative evolutionary algorithms may improve the forecasting performance of symbolic regression-based quantified expectations.

\section{Acknowledgements}

This paper has been partially financed by the project SpeechTech4All (TEC201238939-C03-02). We wish to thank Johanna Garnitz at the Ifo Institute for Economic Research in Munich for providing us the data used in the study.

\section{References}

Abberger, K. (2007) Qualitative business surveys and the assessment of employment - A case study for Germany. International Journal of Forecasting 23: 249-258.

Acosta-González, E., and Fernández, F. (2014) Forecasting financial failure of firms via genetic algorithms. Computational Economics 43: 133-157.

Acosta-González, E., Fernández, F., and Sosvilla, S. (2012) On factors explaining the 2008 financial crisis. Economics Letters 115: 215-217.

Álvarez-Díaz, M., and Álvarez, A. (20005) Genetic multi-model composite forecast for nonlinear prediction of exchange rates. Empirical Economics 30: 643-663.

Anderson, O. (1951) Konjunkturtest und Statistik. Allgemeines Statistical Archives 35: 209220.

Anderson, O. (1952) The business test of the IFO-Institute for economic research, Munich, and its theoretical model. Revue de l'Institut International de Statistique 20: 1-17.

Back, T., Fogel, D. B., and Michalewicz, Z. (1997) Handbook of evolutionary computation. IOP Publishing: Bristol, UK.

Balcombe, K. (1996). The Carlson-Parkin Method Applied to NZ Price Expectations using QSBO Survey Data. Economics Letters 51: 51-57.

Barmpalexis, P., Kachrimanis, K., Tsakonas, A., and Georgarakis, E. (2011) Symbolic regression via genetic programming in the optimization of a controlled release pharmaceutical formulation. Chemometrics and Intelligent Laboratory Systems 107: 75-82.

Batchelor, R. A. (1982) Expectations, output and inflation: the European experience. European Economic Review 17, 1-25.

Batchelor, R. A. (1986) Quantitative v. qualitative measures of inflation expectations. Oxford Bulletin of Economics and Statistics 48: 99-120.

Batchelor, R., and Dua, A. B. (1992) Survey expectations in the time series consumption function. The Review of Economics and Statistics 74: 598-606.

Batchelor, R., and Dua, A. B. (1998) Improving macro-economic forecasts. International Journal of Forecasting 14: 71-81.

Batchelor, R., and Orr, A. B. (1988) Inflation expectations revisited. Economica 55: 317-331. 
Bennett, A. (1984) Output expectations of manufacturing industry. Applied Economics 16: 869879.

Bergström, R. (1995) The relationship between manufacturing production and different business survey series in Sweden 1968-1992. International Journal of Forecasting 11: 379-393.

Berk, J. M. (1999) Measuring inflation expectations: a survey data approach. Applied Economics 31: 1467-1480.

Biart, M., and Praet, P. (1987) The contribution of opinion surveys in forecasting aggregate demand in the four main EC countries. Journal of Economic Psychology 8. 409-428.

Breitung, J., and Schmeling, M. (2013) Quantifying survey expectations: What's wrong with the probability approach? International Journal of Forecasting 29: 142-154.

Cai, W., Pacheco-Vega, A., Sen, M., and Yang, K. T. (2006) Heat transfer correlations by symbolic regression. International Journal of Heat and Mass Transfer 49: 4352-4359.

Can, B., and Heavey, C. (2011) Comparison of experimental designs for simulation-based symbolic regression of manufacturing systems. Computers \& Industrial Engineering 61: 447-462.

Carlson, J. A., and Parkin, M. (1975) Inflation expectations. Economica 42: 123-138.

Ceperic, V., Bako, N., and Baric, A. (2014) A symbolic regression-based modelling strategy of AC/DC rectifiers for RFID applications. Expert Systems with Applications 41: 7061-7067.

CESifo World Economic Survey (2011), Volume 10, No. 2, May 2011.

Chen, R., Liang, C. Y., Hong, W. C., and Gu, D. X. (2015) Forecasting holiday daily tourist flow based on seasonal support vector regression with adaptive genetic algorithm. Applied Soft Computing 26: 435-443.

Claveria, O. (2010) Qualitative survey data on expectations. Is there an alternative to the balance statistic?. In A. T. Molnar (Ed.) Economic Forecasting (pp. 181-190). Nova Science Publishers: Hauppauge NY.

Claveria, O., and Datzira, J. (2010) Forecasting Tourism Demand Using Consumer Expectations. Tourism Review 65: 18-36.

Claveria, O., Pons, E., and Ramos, R. (2007) Business and consumer expectations and macroeconomic forecasts. International Journal of Forecasting 23: 47-69.

Claveria, O., Pons, E., and Suriñach, J. (2003) Las encuestas de opinión empresarial como instrumento de control y predicción de los precios industriales. Cuadernos Aragoneses de Economía 13: 517-530.

Claveria, O., Pons, E., and Suriñach, J. (2006) Quantification of expectations. Are they useful for forecasting?. Economic Issues 11: 19-38.

Common, M. (1985) Testing for Rational Expectations with Qualitative Survey Data. Manchester School of Economic and Social Statistics 53: 138-148.

Cooley, T. F., and Prescott, E. C. (1976) Estimation in the Presence of Stochastic Parameter Variation. Econometrica 44: 167-84.

Cramer, N. (1985) A representation for the adapative generation of simple sequential programs. Proceedings of the International Conference on Genetic Algorithms and their Applications, 24-26 June. Pittsburgh, PA.

Dabhi, V. K., and Chaudhary, S. (2015) Empirical modeling using genetic programming: a survey of issues and approaches. Natural Computing 14: 303-330.

Dasgupta, S., and Lahiri, K. (1992) A comparative study of alternative methods of quantifying qualitative survey responses using NAPM data. Journal of Business and Economic Statistics 10: 391-400.

Dees, S., and Brinca, P. S. (2013) Consumer confidence as a predictor of consumption spending: Evidence for the United States and the Euro area. International Economics 134: $1-14$.

Defris, L. V., and Williams, R. A. (1979) Quantitative versus qualitative measures of price expectations. Economics Letters 2: 169-173.

Driver, C., and Urga, G. (2004) Transforming Qualitative Survey Data: Performance Comparisons for the UK. Oxford Bulletin of Economics and Statistics 66: 71-89.

Ferreira, C. (2001) Gene expression programming: a new adaptive algorithm for solving problems. Complex Systems 13: 87-129. 
Fishe, R. P. H., and Lahiri, K. (1981) On the estimation of inflationary expectations from qualitative responses. Journal of Econometrics 16: 89-102.

Fogel, D. B. (2006) Evolutionary computation. Toward a new philosophy of machine intelligence (Third Edition). John Wiley \& Sons: Hoboken, NJ.

Fogel, L. J., Owens, A. J., and Walsh, M. J. (1966) Artificial intelligence through simulated evolution. John Wiley: NY.

Foster, J., and Gregory, M. (1987) Inflation expectations: the use of qualitative survey data. Applied Economics 9: 319-329.

Franses, P. H., Kranendonk, H. C., and Lanser, D. (2011) One model and various experts: Evaluating Dutch macroeconomic forecasts. International Journal of Forecasting 27: 482495.

Gandomi, A. H., and Roke, D. A. (2015) Assessment of artificial neural network and genetic programming as predictive tools. Advances in Engineering Software 88: 63-72.

Ghonghadze, J., and Lux, T. (2012) Modelling the dynamics of EU economic sentiment indicators: An interaction-based approach. Applied Economics 44: 3065-3088.

Girardi, A. (2014) Expectations and macroeconomic fluctuations in the euro area. Economics Letters 125: 315-318.

Goldberg, D. E. (1989) Genetic algorithms in search, optimization, and machine learning. Addison-Wesley: Reading Boston, MA.

Graff, M. (2010) Does a multi-sectoral design improve indicator-based forecasts of the GDP growth rate? Evidence from Switzerland. Applied Economics 42: 2759-2781.

Guizzardi, A., and Stacchini, A. (2015) Real-time Forecasting Regional Tourism with Business Sentiment Surveys. Tourism Management 47: 213-223.

Hansson, J., Jansson, P., and Löf, M. (2005) Business survey data: Do they help in forecasting GDP growth?. International Journal of Forecasting 30: 65-77.

Hao, J. X., Yu, Y., Law, R., and Fong, D. K. C. (2015) A genetic algorithm-based learning approach to understand customer satisfaction with OTA websites. Tourism Management 48: 231-241.

Henzel, S., and Wollmershäuser, T. (2005) An alternative to the Carlson-Parkin method for the quantification of qualitative inflation expectations: Evidence from the Ifo World Economic Survey. Journal of Business Cycle Measurement and Analysis 2: 321-352.

Holland, J. H. (1975) Adaptation in natural and artificial systems. University of Michigan Press: Ann Arbor, MI.

Hutson, M., Joutz, F., and Stekler, H. (2014) Interpreting and evaluating CESIfo's World Economic Survey directional forecasts. Economic Modelling 38: 6-11.

Hyndman, R. J., and Koehler, A. B. (2006) Another look at measures of forecast accuracy. International Journal of Forecasting 22: 679-688.

Ilmakunnas, P. (1989) Survey expectations vs. rational expectations in the estimation of a dynamic model: demand for labour in Finish manufacturing. Oxford Bulletin of Economics and Statistics 59: 297-314.

Ivaldi, M. (1992) Survey evidence on the rationality of expectations. Journal of Applied Econometrics 7: 225-241.

Jean-Baptiste, F. (2012) Forecasting with the new Keynesian Phillips curve: Evidence from survey data. Economics Letters 117: 811-813.

Jonsson, T., and Österholm, P. (2011) The forecasting properties of survey-based wage-growth expectations. Economics Letters 113: 276-281.

Jonsson, T., and Österholm P. (2012) The properties of survey-based inflation expectations in Sweden. Empirical Economics 42:79-94.

Kariya T. (1990) A generalization of the Carlson-Parkin method for the estimation of expected inflation rate. The Economic Studies Quarterly 41: 155-165.

Kauppi, E., Lassila, J., and Teräsvirta, T. (1996) Short-term forecasting of industrial production with business survey data: experience from Finland's great depression 1990-1993. International Journal of Forecasting 12: 373-381.

Klein LR, Özmucur S. (2010) The use of consumer and business surveys in forecasting. Economic Modelling 27: 1453-1462. 
Klúčcik, M. (2012) Estimates of foreign trade using genetic programming. Proceedings of the 46 the scientific meeting of the Italian Statistical Society.

Kotanchek, M. E, Vladislavleva, E. Y., Smits, G. F. (2010) Symbolic Regression Via Genetic Programming as a Discovery Engine: Insights on Outliers and Prototypes. In: R. Riolo et al., (Eds.), Genetic Programming Theory and Practice VII, Genetic and Evolutionary Computation Vol. 8., 55-72. Springer Science+Business Media, LLC.

Koza, J. R. (1992) Genetic programming: On the programming of computers by means of natural selection. MIT Press: Cambridge, MA.

Kronberger, G., Fink, S., Kommenda, M., and Affenzeller, M. (2011) Macro-economic Time Series Modeling and Interaction Networks. In: C. Di Chio et al. (Eds.): EvoApplications, Part II, 101-110, LNCS 6625.

Lahiri, K., and Zhao, Y. (2015) Quantifying Survey Expectations: A Critical Review and Generalization of the Carlson-Parkin method. International Journal of Forecasting 31: 5162.

Leduc, S., and Sill, K. (2013) Expectations and Economic Fluctuations: An Analysis Using Survey Data. The Review of Economics and Statistics 95: 1352-1367.

Lee, K. C. (1994) Formation of Price and Cost Inflation Expectations in British Manufacturing Industries: a Multi-sectoral Analysis. Economic Journal 104, 372-385.

Lemmens, A., Croux, C., and Dekimpe, M. G. (2005) On the predictive content of production surveys: A pan-European study. International Journal of Forecasting 21: 363-375.

Lemmens, A., Croux, C., and Dekimpe, M. G. (2008) Measuring and testing Granger causality over the spectrum: An application to European production expectation surveys. International Journal of Forecasting 24: 414-431.

Löffler, G. (1999) Refining the Carlson-Parkin method. Economics Letters, 64, 167-71.

Lui, S., Mitchell, J., and Weale, M. (2011a) The utility of expectational data: firm-level evidence using matched qualitative-quantitative UK surveys. International Journal of Forecasting 27: 1128-1146.

Lui, S., Mitchell, J., and Weale, M. (2011b) Qualitative business surveys: signal or noise?. Journal of The Royal Statistical Society, Series A (Statistics in Society) 174(2): 327-348.

Łyziak, T. (2013) Formation of Inflation Expectations by Different Economic Agents. The Case of Poland. Eastern European Economics 51: 5-33.

Łyziak, T., and Mackiewicz-Łyziak, J. (2014) Do Consumers in Europe Anticipate Future Inflation? Eastern European Economics 52: 5-32.

Martinsen, K., Ravazzolo, F., and Wulfsberg, F. (2014) Forecasting macroeconomic variables using disaggregate survey data. International Journal of Forecasting 30: 65-77.

Mitchell, J. (2002) The use of non-normal distributions in quantifying qualitative survey data on expectations. Economics Letters 76: 101-107.

Mitchell, J., Mouratidis, K., and Weale, M. (2007) Uncertainty of UK Manufacturing: Evidence from Qualitative Survey data. Economic Letters 94: 245-252.

Mitchell, J., Smith, R., and Weale, M. (2002) Quantification of qualitative firm-level survey data. Economic Journal 112: 117-135.

Mitchell, J., Smith, R., and Weale, M. (2005a) Forecasting manufacturing output growth using firm-level survey data. The Manchester School 73: 479-499.

Mitchell, J., Smith, R., and Weale, M. (2005b) And indicator of monthly GDP and an early estimate of quarterly GDP growth. The Economic Journal 115(501): F108-F129.

Mittnik, S., and Zadrozny, P. (2005) Forecasting quarterly German GDP at monthly intervals using monthly IFO business conditions data (2005). In JE Sturm, T Wollmershäuser (Eds.), IFO survey data in business cycle analysis and monetary policy analysis (pp. 19-48). Physica-Verlag: Heidelberg.

Mokinski, F., Sheng, X., and Yang, J. (2015) Measuring disagreement in qualitative expectations. Journal of Forecasting 34: 405-426.

Müller, C. (2009) The information content of qualitative survey data. Journal of Business Cycle Measurement and Analysis 2: 1-12.

Müller, C. (2010) You CAN Carlson-Parkin. Economics Letters 108: 33-35. 
Nardo, M. (2003) The quantification of qualitative data: a critical assessment. Journal of Economic Surveys 17: 645-668.

Nardo, M., and Cabeza-Gutés, M. (1999) The role of measurement error in rational expectation testing. Working paper 451, Universitat Autònoma de Barcelona, Barcelona.

Nolte, I., and Pohlmeier, W. (2007) Using forecasts of forecasters to forecast. International Journal of Forecasting 23: 15-28.

O’Neill, M., Vanneschi, L., Gustafson, S., and Banzhaf, W. (2010) Open issues in genetic programming. Genetic Programming and Evolvable Machines, 11: 339-363.

Paloviita, M. (2006) Inflation dynamics in the euro area and the role of expectations. Empirical Economics 31:847-860.

Papadia, F. (1983) Inflationary expectations in the European Economic Communities countries. Empirical Economics 8: 187-202.

Parigi, G., and Schlitzer, G. (1995) Quarterly forecasts of the Italian business-cycle by means of monthly economic indicators. Journal of Forecasting 14: 117-141.

Pehkonen, J. (1992) Survey expectations and stochastic trends in modelling the employment-output equation. Oxford Bulletin of Economics and Statistics 54, 579-589.

Peng, Y., Yuan, C., Qin, X., Huang, J., and Shi, Y. (2014) An improved gene expression programming approach for symbolic regression problems. Neurocomputing 137: 293-301.

Pesaran, M. H. (1984) Expectation formation and macroeconomic modelling. In P. Malgrange and P. A. Muet (Eds.), Contemporary Macroeconomic Modelling. Basil Blackwell: Oxford.

Pesaran, M. H. (1987) The limits to rational expectations. Basil Blackwell: Oxford.

Pesaran, M. H., and Weale, M. (2006) Survey expectations. In G. Elliott, C. W. J. Granger, and A. Timmermann (Eds.), Handbook of economic forecasting, vol. 1 (pp. 715-776). Elsevier North- Holland: Amsterdam.

Poli, R., Vanneschi, L., Langdon, W. B., and Mcphee, N. F. (2010) Theoretical results in genetic programming: the next ten years?. Genetic Programming and Evolvable Machines 11: $285-320$.

Rahiala, M., and Teräsvirta, T. (1993) Business survey data in forecasting the output of Swedish and Finnish metal and engineering industries: a Kalman Filter approach. Journal of Forecasting 12: 255-271.

Robinzonov, N., Tutz, G., and Hothorn, T. (2012) Boosting techniques for nonlinear time series models. AStA Advances in Statistical Analysis 96: 99-122.

Sarradj, E., and Geyer, T. (2014) Symbolic regression modeling of noise generation at porous airfoils. Journal of Sound and Vibration 333: 3189-3202.

Schmeling, M., and Schrimpf, A. (2011) Expected inflation, expected stock returns, and money illusion: What can we learn from survey expectations. European Economic Review 55: 702719.

Seitz, H. (1988) The Estimation of Inflation Forecasts from Business Survey Data. Applied Economics 20, 427-38.

Smith, J., and McAleer, M. (1995) Alternative procedures for converting qualitative response data to quantitative expectations: an application to Australian manufacturing. Journal of Applied Econometrics 10: 165-185.

Sorić, P., Škrabić, B., and Čižmešija, M. (2013) European integration in the light of business and consumer surveys. Eastern European Economics 51: 5-20.

Stangl, A. (2007) Ifo World Economic Survey micro data. Journal of Applied Social Science Studies 127: 487-496.

Stangl, A. (2008) Essays on the measurement of economic expectations. Dissertation. Universität München, Munich.

Terai, A. (2009) Measurement error in estimating inflation expectations from survey data: an evaluation by Monte Carlo simulations. Journal of Business Cycle Measurement and Analysis 2: 133-156.

Theil, H. (1952). On the time shape of economic microvariables and the Munich Business Test. Revue de l'Institut International de Statistique 20: 105-20.

Toyoda, T. (1979) Formation of inflation expectations in Japan. Economic Studies Quarterly 30: 193-201. 
Vermeulen, P. (2014) An evaluation of business survey indices for short-term forecasting: Balance method versus Carlson-Parkin method. International Journal of Forecasting 30: 882-897.

Visco, I. (1984) Price expectations in rising inflation. North-Holland: Amsterdam.

Vladislavleva, E., Smits, G., den Hertog, D., (2010) On the importance of data balancing for symbolic regression. IEEE Transactions in Evolutionary Computation 14: 252-277.

Wei, L. Y. (2013) A hybrid model based on ANFIS and adaptive expectation genetic algorithm to forecast TAIEX. Economic Modelling 33: 893-899.

Wu, C. H., Chou, H. J., and Su, W. H. (2008) Direct transformation of coordinates for GPS positioning using the techniques of genetic programming and symbolic regression. Engineering Applications of Artificial Intelligence 21: 1347-1359.

Yang, G., Li, X., Wang, J., Lian, L., and Ma, T. (2015) Modeling oil production based on symbolic regression. Energy Policy 82: 48-61.

Yao, L., Lin, C.-C., (2009) Identification of nonlinear systems by the genetic programmingbased Volterra filter. IET Signal Processing 3: 93-105.

Zanin, L. (2010) The Relationship between changes in the Economic Sentiment Indicator and real GDP growth: a time-varying coefficient approach. Economics Bulletin 30: 837-846.

Zárate, H. M, Sánchez, K., and Marín, M. (2012) Quantification of ordinal surveys and rational testing: An application to the Colombian monthly survey of economic expectations. Revista Colombiana de Estadística 35: 77-108.

Zelinka, I., Oplatkova, Z., and Nolle, L. (2005) Analytic programming - Symbolic regression by means of arbitrary evolutionary algorithms. International Journal of Simulation: Systems, Science and Technology 6: 44-56.

Zelinka, I. (2015) A survey on evolutionary algorithms dynamics and its complexity - Mutual relations, past, present and future. Swarm and Evolutionary Computation. Forthcoming.

Zimmermann, K. F. (1997) Analysis of business surveys. In M. H. Pesaran and P. Schmidt (Eds.), Handbook of Applied Econometrics. Volume II: Microeconomics, Blackwell Publishers, Oxford. 